\title{
Studies on Growth, Crystal Structure and Characterization of Novel Organic Nicotinium Trifluoroacetate Single Crystals
}

\author{
P.V. Dhanaraj and N.P. Rajesh \\ Additional information is available at the end of the chapter
}

http://dx.doi.org/10.5772/53795

\section{Introduction}

Single crystal growth has a prominent role in the present era of rapid scientific and technical advancement, whereas the application of crystals has unbounded limits. New materials are the lifeblood of solid state research and device technology. Nonlinear optical (NLO) crystals have come upon the materials science scene and are being studied by many research groups around the world. These materials operate on light in a way very analogous to the way of semiconductors which operate on electrons to produce very fast electronic switching and computing circuits.

Organic crystals have compounds with carbon atoms as their essential structural elements. The design and synthesis of organic molecules exhibiting NLO properties have been motivated by the tremendous potential for their applications in the fast developing domains of optoelectronics and photonic technologies. The relevance of the organic materials in the present context is, the delocalized electronic structure of $\pi$-conjugated organic compound offers a number of tantalizing opportunities in the applications as NLO materials. Extensive research in the last decades has shown that organic crystals often possess a higher degree of optical nonlinearity than their inorganic counterparts [1, 2]. Some of the advantages of organic materials include inherently high nonlinearity, high electronic susceptibility through high molecular polarizability, fast response time, the ease of varied synthesis, scope for altering the properties by functional substitutions, high damage resistance, relative ease of device processing, etc. Organic materials have another advantage over inorganic materials, in that the properties of organic materials can be optimized by modifying the molecular structure using molecular engineering and chemical synthesis [3]. A very large operating bandwidth modulation in organic electro-optic devices can be obtained through 
its low dielectric constant at low frequencies. Hence they are projected as forefront candidates for fundamental and applied investigations.

In organic materials, there is a strong correlation between structure and nonlinear properties. Thus, in the case of second order nonlinear effects, it has been established that the macroscopic susceptibility of the materials $\chi^{(2)}$, is related to both the magnitude of the molecular nonlinearities, i.e. the first hyperpolarizability $\beta$, and the relative orientation of the molecules in the medium. Therefore, a fundamental limitation for second-order effects to be observed is the non-centrosymmetry requirement, both at the microscopic molecular level and at the macroscopic bulk level. On the other hand, the third order effects described by $\chi^{(3)}$ can be present in any medium. The $\chi^{(3)}$ coefficients are thus essential in centrosymmetric compounds where the second order coefficients equal zero. They are also important in the non-centrosymmetric molecules. Moreover, these $\chi^{(3)}$ coefficients play a part in some experimental determination of $\chi^{(2)}$ coefficients. It is for example the case in electric field induced second harmonic generation [4-6] (EFISHG) experiment or in hyperRayleigh technique [7-10] where the two-photon absorption (TPA), which is third order effect, can induce fluorescence thus making imprecise the determination of the $\beta$ coefficient. An ultimate goal for designing the molecules with large third order nonlinearities is to incorporate them into devices used in all optical signals processing [11, 12]. Nonlinear optical absorption (NOA) has shown its potential application in optical information storage, all optical logic gates, laser radiation protection, and locked laser mode. Interest in searching for NOA materials has been gradually increased. Organic molecules have been the subjects of great attention due to their potential applications in nonlinear optics, optical switching, and light emitting diodes. Indeed, the potential use of organic device materials in optoelectronics is now a very serious matter.

In order to achieve good macroscopic nonlinear response in organic crystals, one requires an increase in the number of $\pi$ electrons and $\pi$ delocalization length, so as to lead to high molecular hyperpolarizability and also proper orientation of the molecule in the solid-state structure to facilitate high-frequency conversion efficiency. Effective materials generally contain donor and acceptor groups positioned at either end of suitable conjugation path. The increased effective conjugation and the large $\pi$ delocalization length have been recognized as the factors leading to the large third order nonlinearities. While the engineering for enhancing second order NLO efficiency is relatively well understood, the need for efficient third order molecules and materials still exists. The design of organic polar crystals for the quadratic NLO applications is supported by the observation that organic molecules containing $\pi$ electron systems asymmetrized by electron donor and acceptor groups are highly polarizable entities [13]. Donor/acceptor benzene derivatives are sure to produce high molecular nonlinearity. So far, many organic Donor- $\pi-$ Acceptor $(D-\pi-A)$ type compounds have been studied theoretically and also experimentally [14]. The studies indicate that the organic D- $\pi-\mathrm{A}$ compounds are highly promising candidates for NLO applications.

Nicotinic acid, a B vitamin also known as niacin, and its derivatives have been studied extensively over the last decade due to their biological and chemical importance. Niacin forms coordination complexes with tin (Sn), which have been found to have better 
antitumor activity than the well-known cis-platin or doxorubicin [15]. Many of its pharmacological properties are detailed in literature [16-18]. The reported structures of complexes reveal that nicotinic acid and its derivatives acting as bridging ligands through the carboxylate group and pyridyl $\mathrm{N}$ atom [19]. We have synthesized the crystalline salt of nicotinium trifluoroacetate and their crystals in monoclinic system were grown by using solution growth technique for the first time. The crystal structure of nicotinium trifluoroacetate in triclinic system has reported by S. Athimoolam and S. Natarajan [20]. Here we report monoclinic polymorph of nicotinium trifluoroacetate, its asymmetric unit contains a protonated nicotinium cation and a trifluroacetate anion. This chapter discusses synthesis, solubility, crystal growth, structural, dielectric and mechanical properties of nicotinium trifluoroacetate (NTF). Thermal properties of NTF were analyzed and compared with that of two nicotinium derivative crystals nicotinium oxalate and nicotinium nitrate monohydrate.

\section{Experimental studies}

\subsection{Synthesis of NTF}

NTF was synthesized by the reaction between nicotinic acid (SRL, India) and trifluoroacetic acid (Merck) taken in equimolar ratio. The growth solution was prepared by adding calculated amount of trifluoroacetic acid slowly in saturated aqueous solution of equimolar nicotinic acid at $50{ }^{\circ} \mathrm{C}$. The continuous stirring of the solution for $6 \mathrm{~h}$ at constant temperature using a temperature controlled magnetic stirrer yielded the precipitate of crystalline substance of NTF. Repeated crystallization and filtration processes were applied for the purification of the synthesized compound.

\subsection{Determination of solubility and metastable zone width}

The nucleation studies were carried out in a constant temperature bath (CTB) with cooling facility of accuracy of $\pm 0.01{ }^{\circ} \mathrm{C}$. The solubility at $30{ }^{\circ} \mathrm{C}$ was determined by dissolving the recrystallized salt of NTF in $100 \mathrm{ml}$ Millipore water of resistivity $18.2 \mathrm{M} \Omega \mathrm{cm}$ taken in an air tight container. The solution was stirred continuously for $6 \mathrm{~h}$ to achieve stabilization using an immersible magnetic stirrer. After attaining the saturation, the concentration of the solute was estimated gravimetrically. The same procedure is repeated for different temperatures $\left(35,40,45\right.$ and $\left.50^{\circ} \mathrm{C}\right)$.

Metastable zone width is an essential parameter for the growth of large size crystals from solution, since it is the direct measure of the stability of the solution in its supersaturated region. The metastable zone width was measured by adopting the conventional polythermal method [21]. The saturated solution $(100 \mathrm{ml})$ at $30{ }^{\circ} \mathrm{C}$ was prepared according to the presently determined solubility data. After attaining the saturation, the solution was filtered by the filtration pump and Whatman filter paper of pore size $11 \mu \mathrm{m}$. The solution was preheated to $5{ }^{\circ} \mathrm{C}$ above the saturated temperature for homogenization and left at the superheated temperature for about $1 \mathrm{~h}$ before cooling. Then it was slowly cooled at a 
desired cooling rate of $4{ }^{\circ} \mathrm{C} / \mathrm{h}$, until the first crystal appeared. The temperature was instantly recorded. The difference between the saturation temperature and nucleation temperature gives the metastable zone width of the system. Then experiment was repeated for different saturation temperatures $35,40,45$ and $50{ }^{\circ} \mathrm{C}$ and the corresponding metastable zone widths were measured. Several runs (3-5 times) were carried out under controlled conditions for the confirmation of the saturation and nucleation points. The measured values of solubility and metastable zone width of NTF are shown in Figure 1. It shows that NTF has good solubility in water and it increases almost linearly with temperature. Hence solution growth could be a better method to grow good quality single crystals of NTF. The value of the metastable zone width depends not only on the temperature but also on the type of the crystal and its physicochemical properties [22]. One can observe that the metastable zone width decreases with increasing temperature.

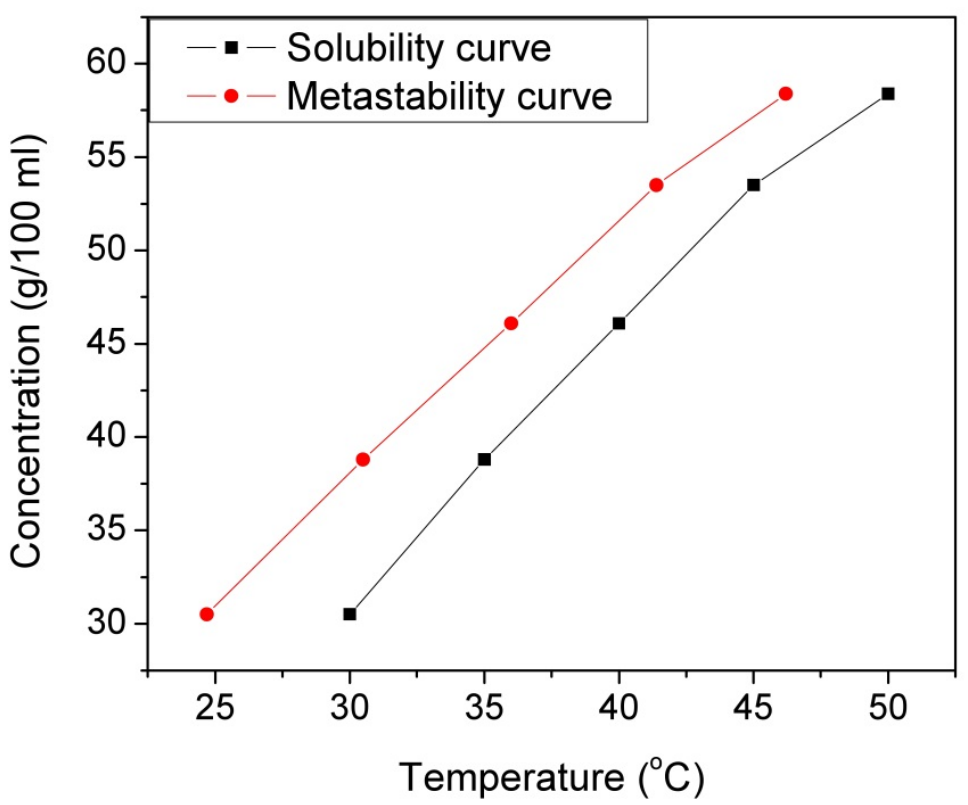

Figure 1. Solubility and metastablity curves of NTF

\subsection{Crystal growth}

Slow evaporation method was employed for growing the single crystals of NTF. The recrystallized salt was used for the preparation of saturated solution at room temperature $\left(35^{\circ} \mathrm{C}\right)$. The solution was filtered by filtration pump and Whatman filter paper of pore size $11 \mu \mathrm{m}$. Then the filtered solution was transferred to a petridish with a perforated lid in order to control the evaporation rate and kept undisturbed in a dust free environment. The single crystal of NTF of size $27 \times 12 \times 7 \mathrm{~mm}^{3}$ was harvested from mother solution after a growth period of 22 days. The grown single crystal of NTF is shown in the Figure 2. 
Morphology of the grown crystals was identified by the single crystal X-ray diffraction studies (Bruker Kappa APEXII). It establishes that the crystal has eight developed faces, out of which (112) and (112) planes are more prominent. For each face, its parallel Friedal plane is also present in the grown crystal and shown diagrammatically in Figure 3.

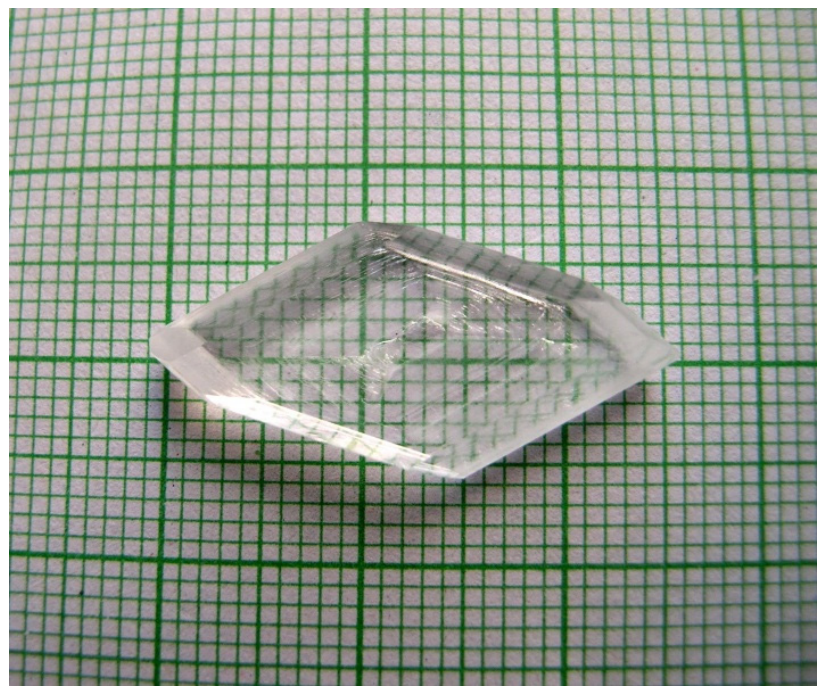

Figure 2. Photograph of as-grown NTF crystal
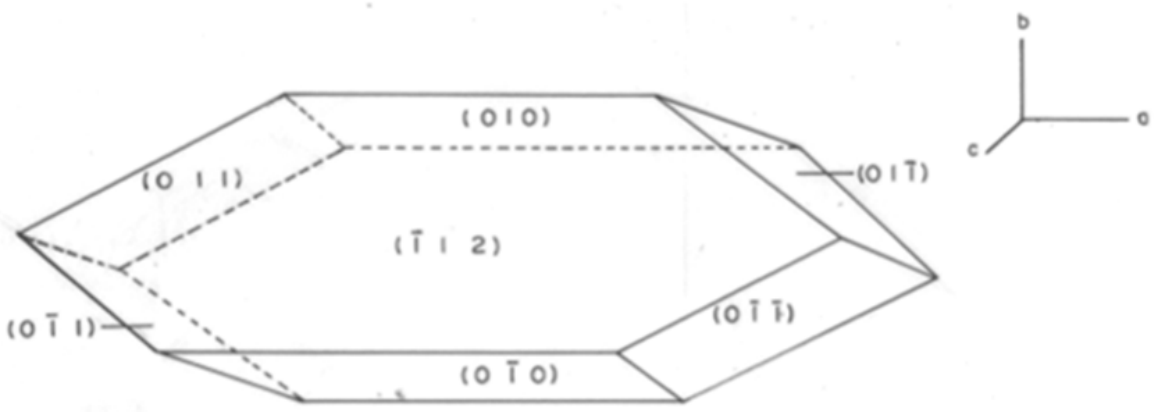

Figure 3. Morphology representation of NTF crystal

\section{Analysis of physicochemical studies}

\subsection{X-ray diffraction analysis}

The unit cell parameters and crystal structure of NTF were determined from single crystal X-ray diffraction data obtained with a four-circle Nonius CAD4 MACH3 diffractometer (graphite monochromated, $\operatorname{MoK} \alpha=0.71073 \AA$ ) at room temperature (293 K). The data reduction was done by using XCAD4 [23] and absorption correction was done by the 
method of $\psi$-scan [24]. The structure solution and refinement were performed using SHELXTL 6.10 [25]. The crystal structure of NTF was solved by direct methods, and fullmatrix least-squares refinements were performed on $\mathrm{F}^{2}$ using all the unique reflections. All the non-hydrogen atoms were refined with anisotropic atomic displacement parameters, and hydrogen atoms were refined with isotropic displacement factors. The crystallographic data and structure refinement parameters of NTF crystal are presented in Table 1. The crystal structure and packing diagram of NTF are shown in Figures 4 and 5 respectively. The $\mathrm{H}$ atom participating in the $\mathrm{N}-\mathrm{H}$ bond was located from the difference Fourier map and all other $\mathrm{H}$ atoms were positioned geometrically and refined using a riding model with $\mathrm{C}-\mathrm{H}$ $=0.93 \AA$ and $\mathrm{O}-\mathrm{H}=0.82 \AA$ with $\operatorname{Uiso}(\mathrm{H})=1.2-1.5 \mathrm{Ueq}$ (parent atom). The absolute configuration is assigned from the starting materials taken for reaction.

\begin{tabular}{|c|c|}
\hline Empirical formula & $\mathrm{C}_{8} \mathrm{H}_{6} \mathrm{~F}_{3} \mathrm{NO}_{4}$ \\
\hline Formula weight & 237.14 \\
\hline Temperature & $293(2) \mathrm{K}$ \\
\hline Wavelength & $0.71073 \AA$ \\
\hline Crystal system, space group & Monoclinic, $I 2 / \mathrm{a}$ \\
\hline Unit cell dimensions & 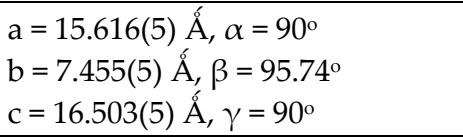 \\
\hline Volume & $1911.6 \AA^{3}$ \\
\hline Z, Calculated density & $8,1.648 \mathrm{~g} / \mathrm{cm}^{3}$ \\
\hline Absorption coefficient & $0.167 \mathrm{~mm}^{-1}$ \\
\hline $\mathrm{F}(000)$ & 960 \\
\hline Crystal size & $0.18 \mathrm{~mm} \times 0.15 \mathrm{~mm} \times 0.13 \mathrm{~mm}$ \\
\hline Theta range for data collection & $2.48-24.96^{\circ}$ \\
\hline Limiting indices & $-18 \leq \mathrm{h} \leq 18,-8 \leq \mathrm{k} \leq 1,-19 \leq 1 \leq 19$ \\
\hline Reflections collected / unique & $3929 / 1680[\mathrm{R}(\mathrm{int})=0.0204]$ \\
\hline Completeness to theta $=24.96$ & $99.6 \%$ \\
\hline Absorption correction & $\psi$ - scan \\
\hline Refinement method & Full-matrix least-squares on $\mathrm{F}^{2}$ \\
\hline Data / restraints / parameters & $1680 / 0 / 194$ \\
\hline Goodness-of-fit on $\mathrm{F}^{2}$ & 1.095 \\
\hline Final $\mathrm{R}$ indices $[\mathrm{I}>2 \sigma(\mathrm{I})]$ & $\mathrm{R}_{1}=0.0353, \mathrm{wR} \mathrm{R}_{2}=0.0905$ \\
\hline $\mathrm{R}$ indices (all data) & $\mathrm{R}_{1}=0.0495, \mathrm{wR}_{2}=0.0976$ \\
\hline Extinction coefficient & $0.0040(7)$ \\
\hline Largest diff. peak and hole & 0.210 and -0.201 e. $\AA^{-3}$ \\
\hline
\end{tabular}

Table 1. Crystallographic data and structure refinement parameters for NTF 
This monoclinic polymorph of NTF crystallized in I2/a space group and the asymmetric unit contains a protonated nicotinium cation and a trifluroacetate anion. The angle between the mean plane of the pyridine ring and the mean plane of the acetate group is $48.93^{\circ}$ where as in the triclinic form [20], it is $14^{\circ}$ and the distance between the anion to cation is $3.134 \AA$ which is $0.463 \AA$ longer than the triclinic form. The structure is stabilized by $\mathrm{N}-\mathrm{H} \cdots \mathrm{O}, \mathrm{O}-$ $\mathrm{H} \cdots \mathrm{O}$ and $\mathrm{C}-\mathrm{H} \cdots \mathrm{O}$ hydrogen bonds and hydrogen bond geometry is given in Table 2 .

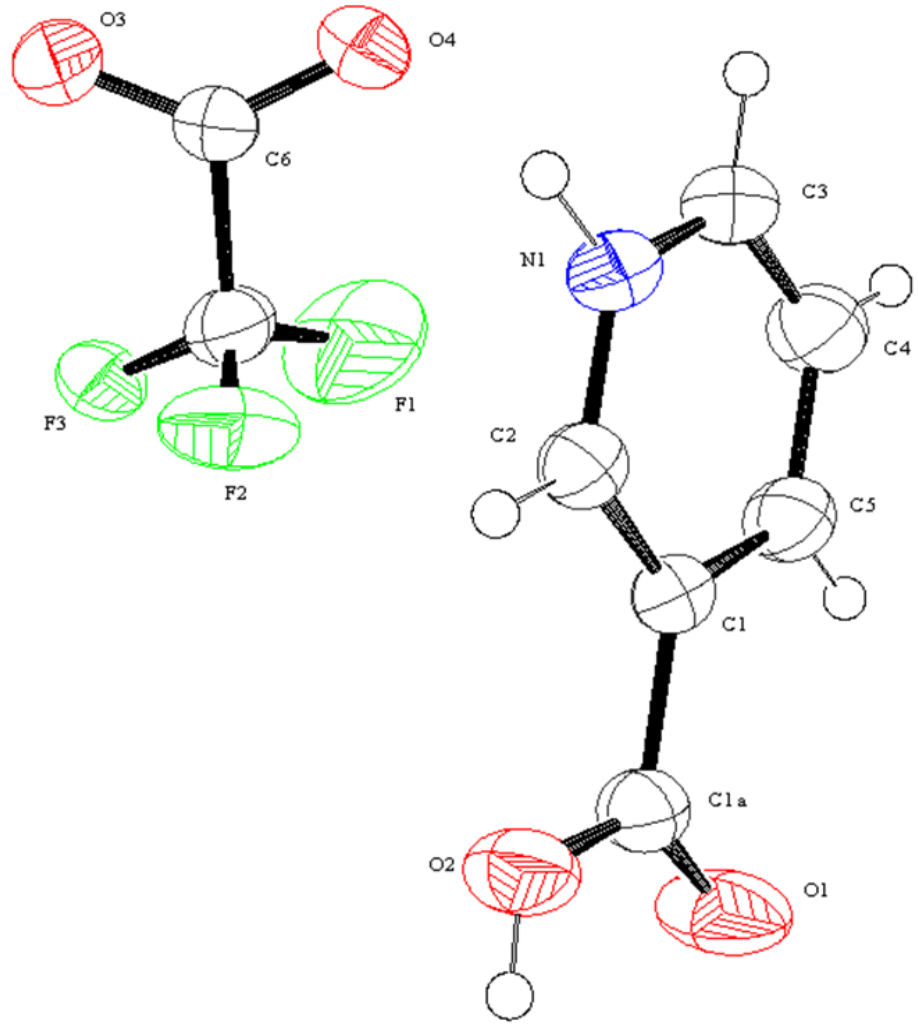

Figure 4. Structure of NTF showing 50\% probability displacement ellipsoids with atom numbering scheme (for clarity, only major components of the disordered fluorine atoms are shown) 


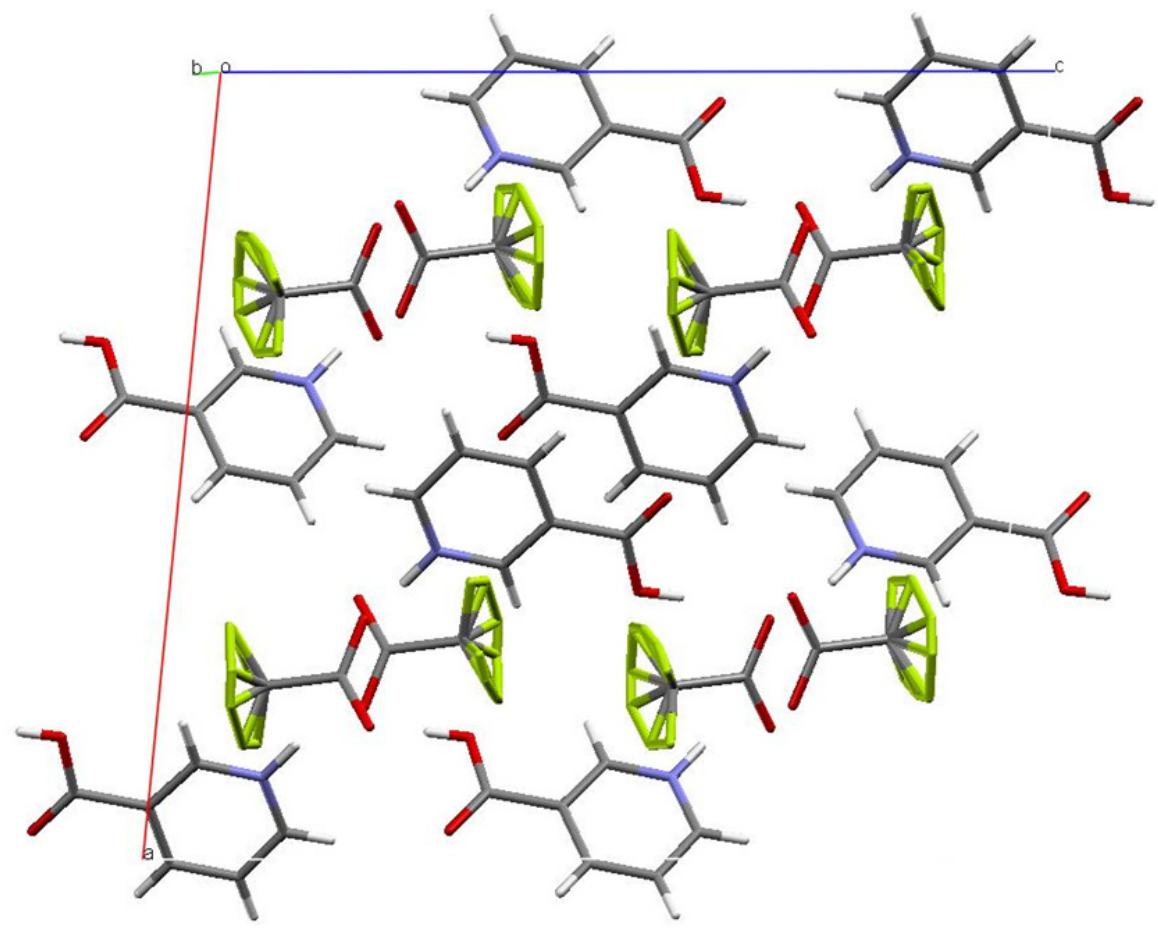

Figure 5. Molecular packing diagram of NTF viewed down the b-axis

\begin{tabular}{|l|l|l|l|l|}
\hline $\mathrm{D}-\mathrm{H} \cdots \mathrm{A}$ & $\mathrm{d}(\mathrm{D}-\mathrm{H})$ & $\mathrm{d}(\mathrm{H} \cdots \mathrm{A})$ & $\mathrm{d}(\mathrm{D} \cdots \mathrm{A})$ & $<($ DHA $)$ \\
\hline $\mathrm{N}(1)-\mathrm{H}(1 \mathrm{~N}) \cdots \mathrm{O}(3)$ & 0.97 & 1.69 & 2.6468 & 167 \\
\hline $\mathrm{O}(2)-\mathrm{H}(2 \mathrm{O}) \cdots \mathrm{O}(4){ }^{\mathrm{i}}$ & 0.82 & 1.74 & 2.5460 & 167 \\
\hline $\mathrm{C}(3)-\mathrm{H}(3) \cdots \mathrm{O}(1)^{\mathrm{ii}}$ & 0.93 & 2.44 & 3.3397 & 163 \\
\hline $\mathrm{C}(4)-\mathrm{H}(4) \cdots \mathrm{O}(3)^{i i i}$ & 0.93 & 2.37 & 3.2929 & 174 \\
\hline
\end{tabular}

Symmetry codes: (i) $1 / 2-x, y,-z$, (ii) $x, 1 / 2-y, 1 / 2+z$ and (iii) $1-x,-1 / 2+y, 1 / 2-z$.

Table 2. Hydrogen bonds geometry of NTF

CCDC No. 779179 contains the supplementary crystallographic data for this paper. These data can be obtained free of charge via www.ccdc.cam.ac.uk/data-request/cif, by e-mailing data-request@ccdc.com.ac.uk or by contacting the Cambridge crystallographic data centre, 12 Union Road, Cambridge CB21 EZ, U.K.; Fax: +44 1223336033.

Powder X-ray diffraction study was carried out by employing SEIFERT, 2002 (DLX model) diffractometer with $\mathrm{CuK}_{\alpha}(\lambda=1.5405 \AA)$ radiation using a tube voltage and current of $40 \mathrm{kV}$ and $30 \mathrm{~mA}$ respectively. The grown crystals were finely powdered and have been subjected to powder XRD analysis. The sample was scanned over the range $10-60^{\circ}$ at the rate of $1 \%$ min. The indexed powder X-ray diffraction pattern of NTF is given in Figure 6 . The well defined Bragg's peaks at specific $2 \theta$ angles confirmed the crystallinity of NTF. 


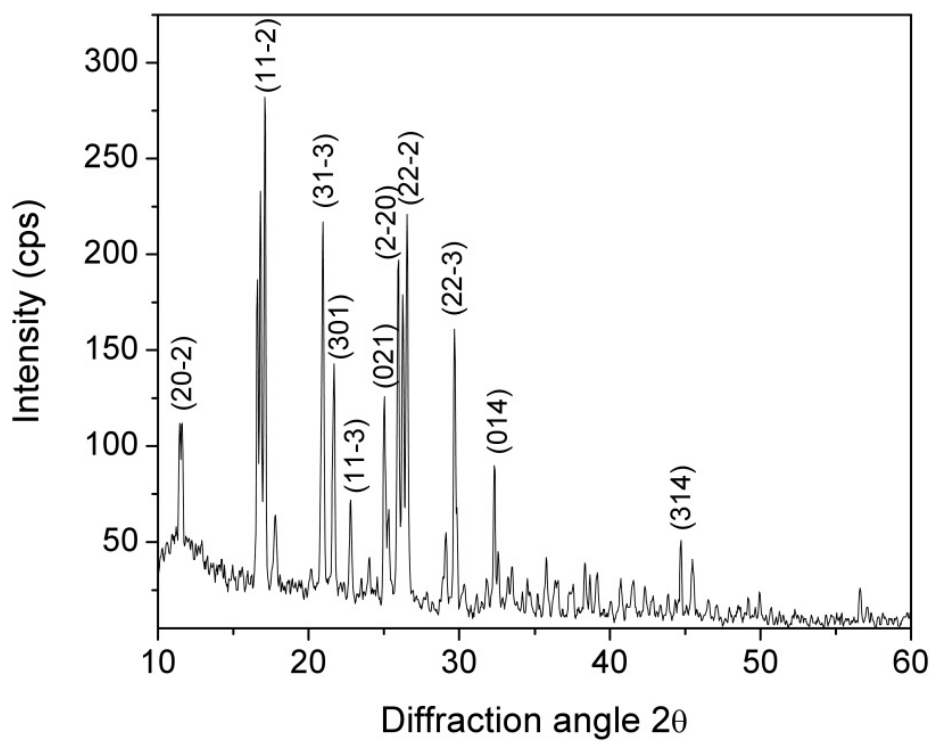

Figure 6. Powder XRD pattern of NTF

\subsection{High-resolution $x$-ray diffraction (HRXRD) analysis}

The crystalline perfection of the grown NTF single crystals was characterized by HRXRD analysis by employing a multicrystal X-ray diffractometer designed and developed at National Physical Laboratory [26]. The schematic diagram of this multicrystal X-ray diffractometer is shown in figure 7. The divergence of the $X$-ray beam emerging from a fine focus X-ray tube (Philips X-ray Generator; $0.4 \mathrm{~mm} \times 8 \mathrm{~mm} ; 2 \mathrm{kWMo}$ ) is first reduced by a long collimator fitted with a pair of fine slit assemblies. This collimated beam is diffracted twice by two Bonse-Hart [27] type of monochromator crystals and the thus diffracted beam contains well resolved $\mathrm{MoK} \alpha_{1}$ and $\mathrm{MoK} \alpha_{2}$ components. The MoK $\alpha_{1}$ beam is isolated with the help of fine slit arrangement and allowed to further diffract from a third (111) Si monochromator crystal set in dispersive geometry $(+,-,-)$. Due to dispersive configuration, though the lattice constant of the monochromator crystal and the specimen are different, the dispersion broadening in the diffraction curve of the specimen does not arise. Such an arrangement disperses the divergent part of the MoK $\alpha_{1}$ beam away from the Bragg diffraction peak and thereby gives a good collimated and monochromatic MoKa beam at the Bragg diffraction angle, which is used as incident or exploring beam for the specimen crystal. The dispersion phenomenon is well described by comparing the diffraction curves recorded in dispersive $(+,-,-)$ and non-dispersive $(+,-,+)$ configurations [28]. This arrangement improves the spectral purity $\left(\Delta \lambda / \lambda<<10^{-5}\right)$ of the MoK $\alpha_{1}$ beam. The divergence of the exploring beam in the horizontal plane (plane of diffraction) was estimated to be $<<3$ arc s. The specimen occupies the fourth crystal stage in symmetrical Bragg geometry for diffraction in $(+,-,-,+)$ configuration. The specimen can be rotated about a vertical axis, which is perpendicular to the plane of diffraction, with minimum angular interval of 0.4 arc 
s. The diffracted intensity is measured by using an in-house developed scintillation counter. To provide two-theta (20в) angular rotation to the detector (scintillation counter) corresponding to the Bragg diffraction angle $(\theta \mathrm{B})$, it is coupled to the radial arm of the goniometer of the specimen stage. The rocking or diffraction curves were recorded by changing the glancing angle (angle between the incident $X$-ray beam and the surface of the

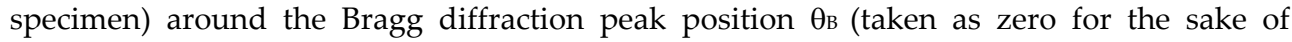
convenience) starting from a suitable arbitrary glancing angle. The detector was kept at the same angular position $20 \mathrm{~B}$ with wide opening for its slit, the so-called $\omega$ scan. This arrangement is very appropriate to record the short range order scattering caused by the defects or by the scattering from local Bragg diffractions from agglomerated point defects or due to low angle and very low angle structural grain boundaries [29].

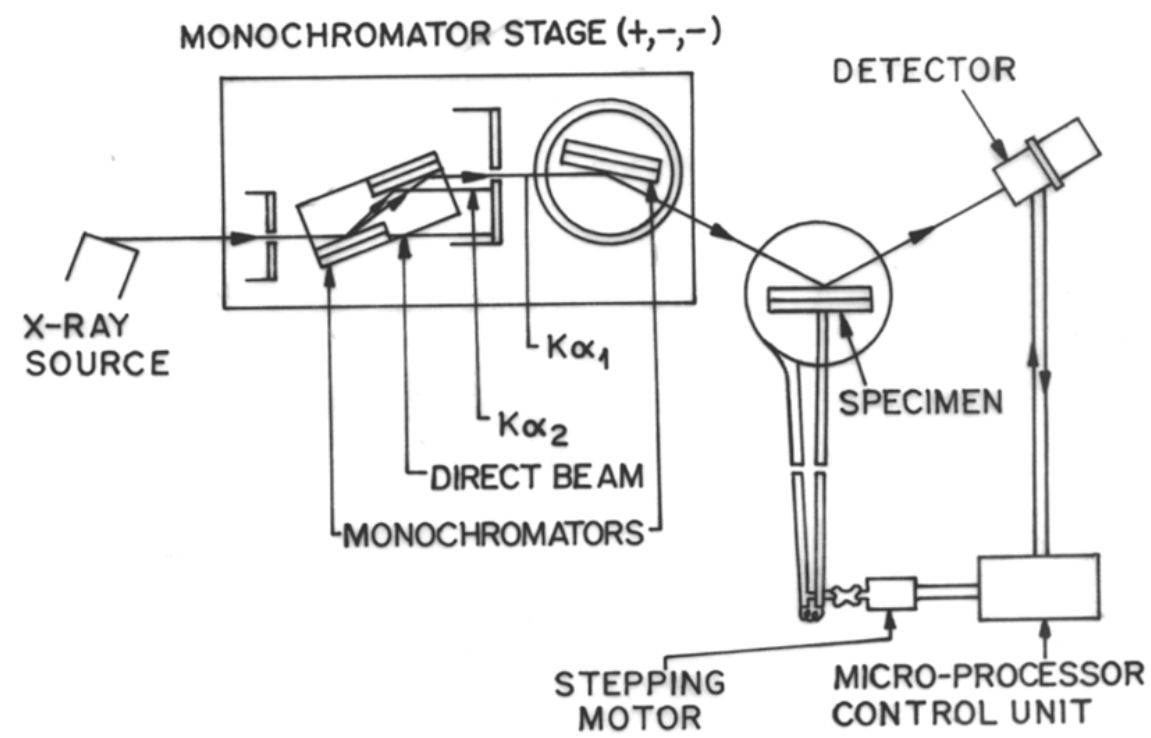

Figure 7. Schematic line diagram of multicrystal X-ray diffractometer designed, developed and fabricated at National Physical Laboratory

Before recording the diffraction curve, to remove the non-crystallized solute atoms remained on the surface of the crystal and also to ensure the surface planarity, the specimen was first lapped and chemically etched in a non preferential etchant of water and acetone mixture in $1: 2$ ratio.

Figure 8 shows the high-resolution X-ray diffraction curve recorded for NTF specimen crystal using $(11 \overline{2})$ diffraction planes using $\operatorname{MoK} \alpha_{1}$ radiation. The solid line (convoluted curve) is well fitted with the experimental points represented by the filled circles. On deconvolution of the diffraction curve, it is clear that the curve contains two additional peaks, which are 18 and 28 arc s away from the main peak (at zero glancing angle). These two additional peaks correspond to two internal structural very low angle (tilt angle $\leq 1$ arc 
min) boundaries [30] whose tilt angles (Tilt angle may be defined as the misorientation angle between the two crystalline regions on both sides of the structural grain boundary) are 18 and 28 arc $s$ from their adjoining regions. The FWHM (full width at half maximum) of the main peak and the very low angle boundaries are respectively 22, 27 and 40 arc s. The low FWHM values and relatively low angular spread of around 200 arc s of the diffraction curve show that the crystalline perfection of the specimen is reasonably good. Thermal fluctuations or mechanical disturbances or segregation of solvent molecules during the growth process could be responsible for the observed very low angle boundaries. It may be mentioned here that such very low angle boundaries could be detected with well resolved peaks in the diffraction curve only because of the high-resolution of the multicrystal X-ray diffractometer used in the present studies.

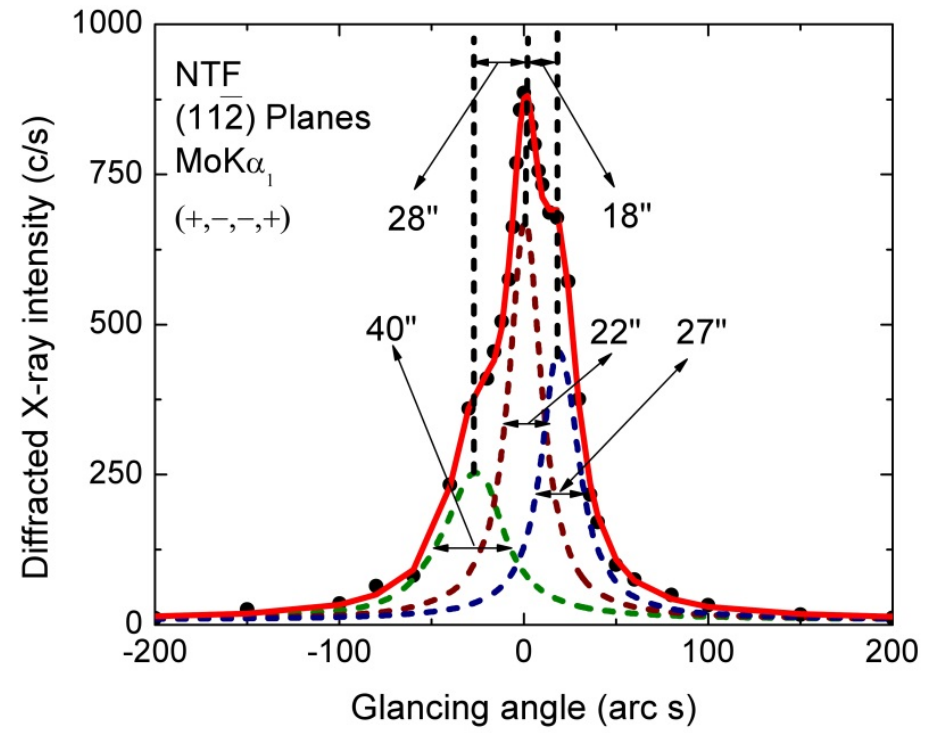

Figure 8. High-resolution X-ray diffraction curve recorded for a typical NTF single crystal specimen using $(11 \overline{2})$ diffracting planes

\subsection{Thermal analysis}

Thermal properties of NTF were analyzed and compared with that of two nicotinium derivative crystals nicotinium oxalate (NOX) and nicotinium nitrate monohydrate (NNM). All these crystals had grown in our laboratory and belong to monoclinic system. Differential thermal analysis (DTA) and thermogravimetric analysis (TGA) of crystals were carried out simultaneously by employing TA instrument Model Q600 SDT thermal analyzer. The sample was heated at a rate of $10{ }^{\circ} \mathrm{C} / \mathrm{min}$ in inert nitrogen atmosphere. Thermal stability of crystals was further tested using differential scanning calorimetry (DSC). DSC study was performed by using TA instrument Model Q20 in the temperature range $50-300{ }^{\circ} \mathrm{C}$ at a 
heating rate of $10{ }^{\circ} \mathrm{C} / \mathrm{min}$ in inert nitrogen atmosphere and sample was placed in the Alumina crucible.

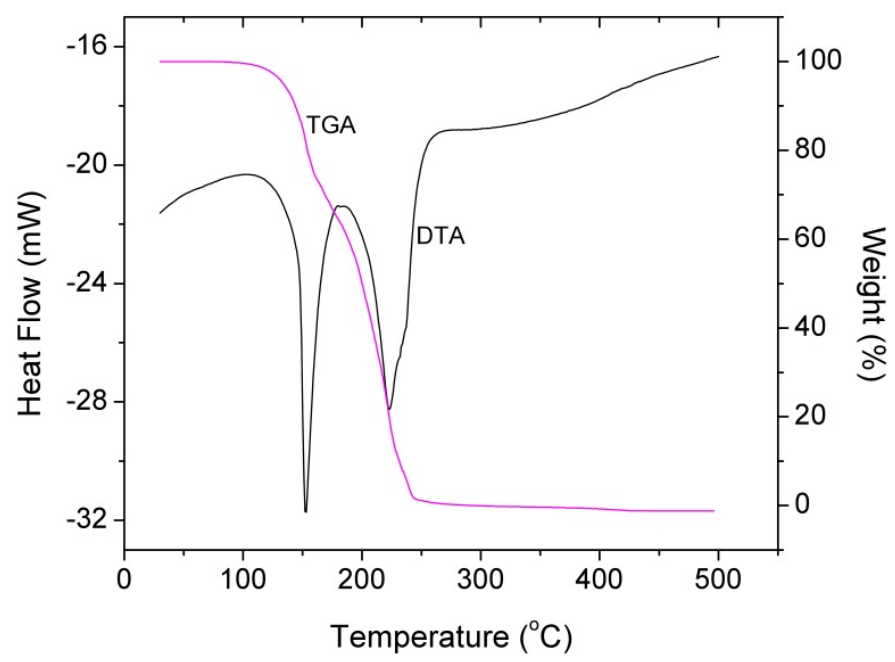

Figure 9. TGA-DTA curves of NTF

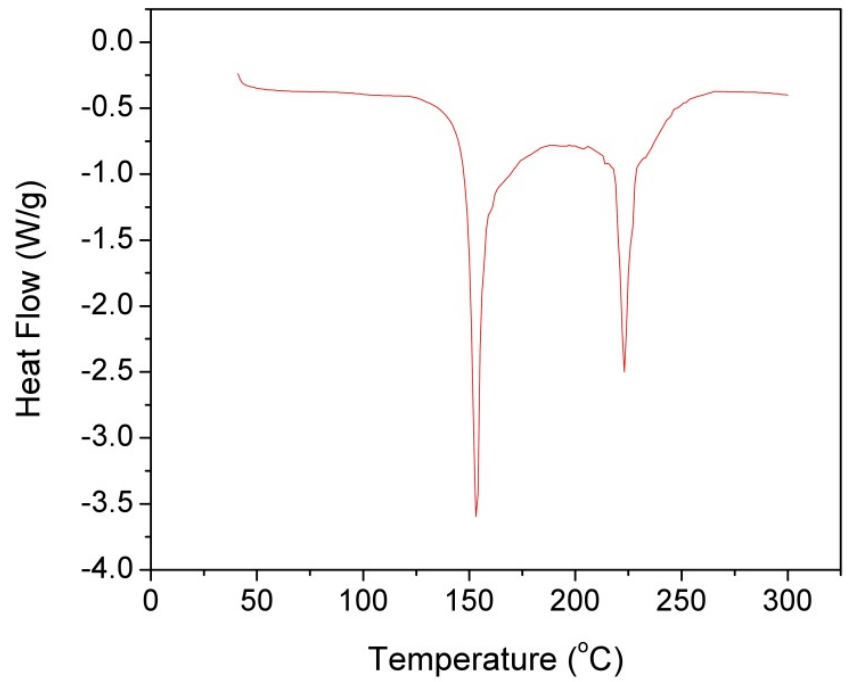

Figure 10. DSC trace of NTF

TG-DTA and DSC curves of NTF were depicted in Figures 9 and 10 respectively. In DTA curve, first endothermic peak at $152{ }^{\circ} \mathrm{C}$ is attributed to meting point of the sample, which is also evident in the DSC curve. Another important observation is that, there is no phase transition till the material melts and this enhances the temperature range for the utility of 
the crystal for NLO applications. The absence of water of crystallization in the molecular structure is indicated by the absence of the weight loss near $100{ }^{\circ} \mathrm{C}$. Further there is no decomposition near the melting point [31]. This ensures the suitability of the material for possible application in lasers, where the crystals are required to withstand high temperatures. The weight loss starts around $110{ }^{\circ} \mathrm{C}$ and weight loss corresponding to decomposition of NTF was observed at $223{ }^{\circ} \mathrm{C}$, which takes place over large temperature range $\left(110-252{ }^{\circ} \mathrm{C}\right)$ where almost all the gaseous fragments like carbon dioxide and ammonia might be liberated. The TGA reveals exactly the same changes shown by DTA. The second endothermic peak in the DTA curve shows that the material is fully decomposed at $223^{\circ} \mathrm{C}$ as confirmed by DSC. The small difference in the shape of the second peak may be due to the presence of impurities. The sharpness of the endothermic peaks shows good degree of crystallinity of the grown sample.

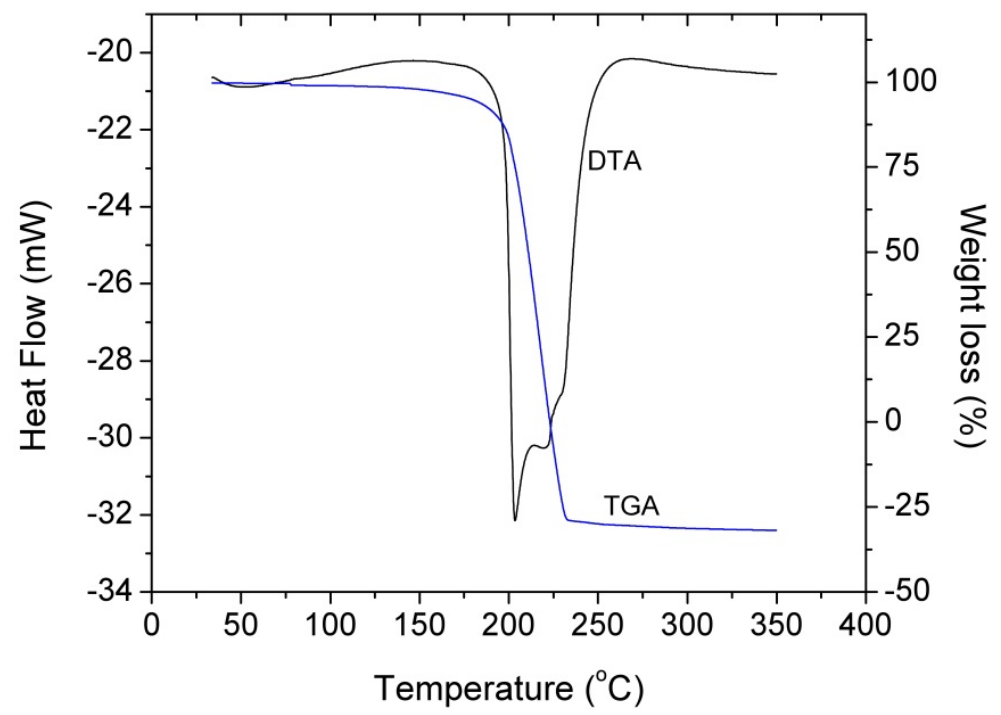

Figure 11. TGA-DTA curves of NOX

In TG-DTA trace of NOX (Figure 11), endothermic peak in DTA trace at $203{ }^{\circ} \mathrm{C}$ represents the melting point of the sample. The absence of water of crystallization in the molecular structure is indicated by the absence of the weight loss around $100{ }^{\circ} \mathrm{C}$. TGA trace reveals that weight loss of the sample starts from this region and at $223^{\circ} \mathrm{C}$ it shows complete weight loss. The shoulder peaks in DTA after the main peak corresponds to the decomposition of the material. There is no phase transition till the material melts and this enhances the temperature range for the utility of the crystal for applications. Under these conditions, phase transition means common phase transition (e.g., solid-to-liquid, liquid-to-gas etc.).

Figure 12 shows the thermogram for DTA and TGA of NNM. The compound starts to lose single molecule of water of crystallization at about $90{ }^{\circ} \mathrm{C}$ and the loss continues up to $102{ }^{\circ} \mathrm{C}$. The weight loss in this temperature range is consistent with the weight of single molecules 
of water present in the crystal. The DTA curve shows a major endothermic peak, which corresponds to the melting point of NNM at $189^{\circ} \mathrm{C}$. The second weight loss take place over the temperature range $135-235^{\circ} \mathrm{C}$ and almost all the compounds decomposed as its gaseous products. The second endothermic peak in the DTA curve at $230{ }^{\circ} \mathrm{C}$ attributed to the decomposition temperature of NNM. Summarized results of thermal analysis of NNM are given in Table 3.

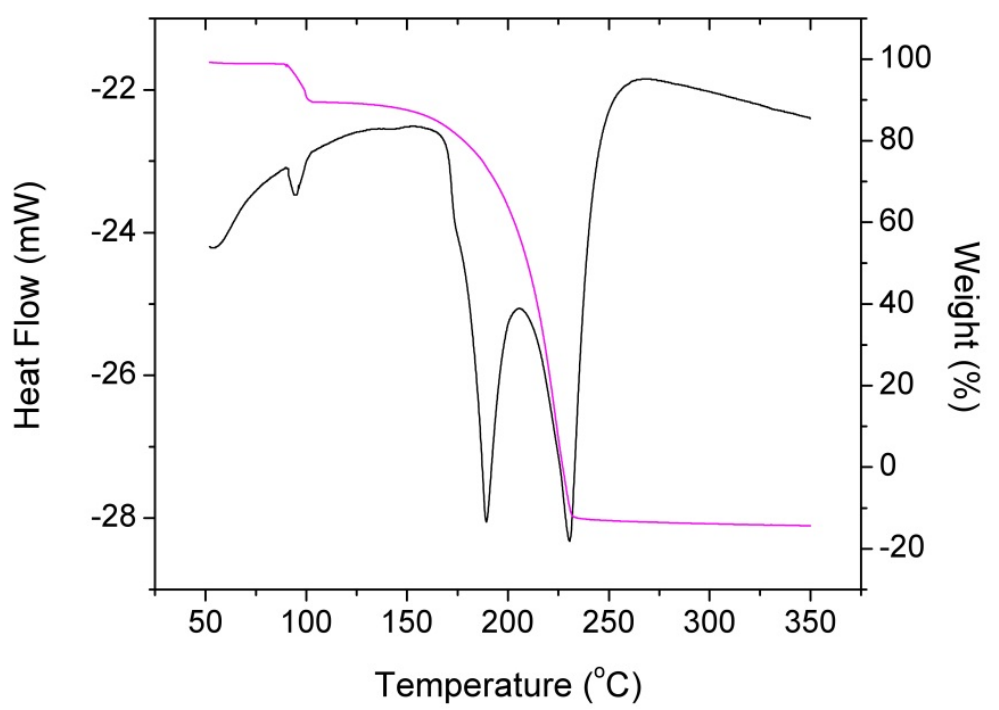

Figure 12. TGA-DTA curves of NNM

\begin{tabular}{lllll}
\hline Stage & $\begin{array}{l}\text { Decomposition } \\
\text { temperature range } \\
\left({ }^{\circ} \mathrm{C}\right)\end{array}$ & Decomposition steps & \multicolumn{2}{c}{ Weight loss (\%) } \\
Calculated
\end{tabular}

Table 3. Summarized TGA and DTA results of NNM

The figure 13 shows the comparison of DSC curves of NTF with other nicotinium derivative crystals. The calculated values of enthalpy for vapourisation, melting reaction and decomposition reaction for these three materials show that enthalpy value for NTF is less than that of NNM and NOX. As the temperature increases, initially NNM loses its single molecule of water of crystallization in the range $90-102{ }^{\circ} \mathrm{C}$. NTF melts at $152{ }^{\circ} \mathrm{C}, \mathrm{NNM}$ at 189 ${ }^{\circ} \mathrm{C}$ and NOX at $203{ }^{\circ} \mathrm{C}$ respectively. Thus thermal stability of NTF is higher than that of NNM but low when compared to NOX. The low thermal stability of NNM is due to vapourisation of its water molecule. 


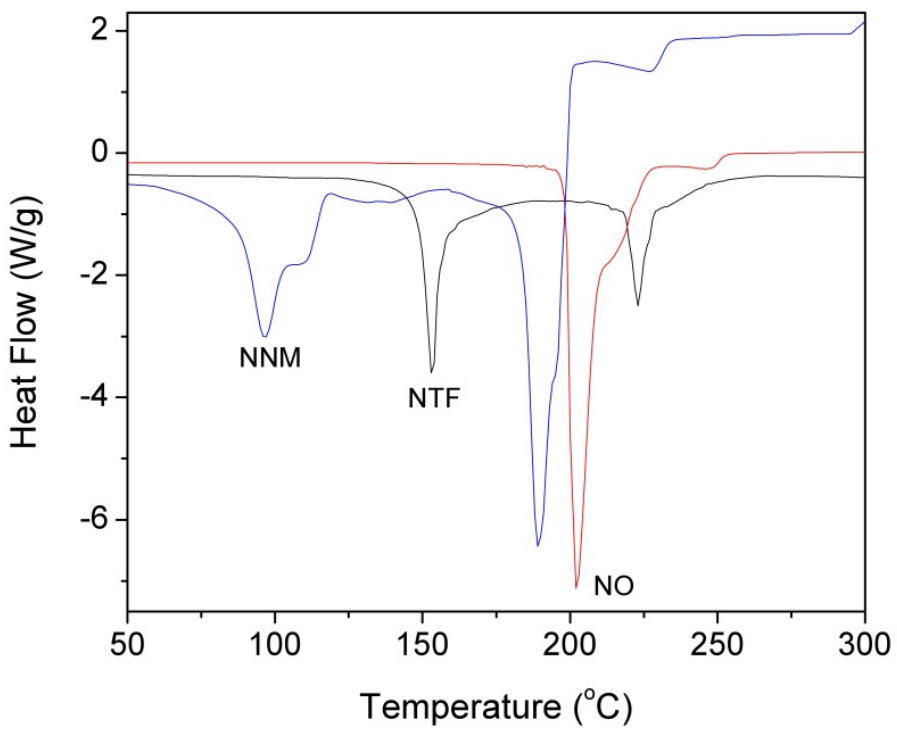

Figure 13. DSC curves of NNM, NTF and NO

\subsection{FTIR studies}

The FTIR spectrum was recorded using Perkin-Elmer FTIR spectrum RXI spectrometer by $\mathrm{KBr}$ pellet technique in the range $400-4000 \mathrm{~cm}^{-1}$ at room temperature $\left(35^{\circ} \mathrm{C}\right)$. In the FTIR spectrum of NTF (Figure 14), the strong band at $3439 \mathrm{~cm}^{-1}$ is attributed to stretching vibrations of $\mathrm{O}-\mathrm{H}$ groups. The peak at $3086 \mathrm{~cm}^{-1}$ corresponds to the aromatic $\mathrm{C}-\mathrm{H}$ stretching vibrations in the ring. $\mathrm{O}-\mathrm{H}$ and $\mathrm{C}-\mathrm{C}$ stretching vibrations are observed at $2809 \mathrm{~cm}^{-1}$ and 1907 $\mathrm{cm}^{-1}$ respectively. The existence of $\mathrm{COO}^{-}$or $\mathrm{COOH}$ groups in the studied crystal was deduced on the basis of vibrational spectra. It is clearly seen that the existence of $\mathrm{COOH}$ is illustrated by the very strong infrared band located at $1708 \mathrm{~cm}^{-1}$. Asymmetric stretching vibration of $\mathrm{COO}^{-}$is observed at $1597 \mathrm{~cm}^{-1}$. The peak at $1420 \mathrm{~cm}^{-1}$ is due to symmetric stretching vibration of COO- The $\mathrm{C}-\mathrm{H}$ vibrations are occurred at $1369 \mathrm{~cm}^{-1}$. C-H in plane bending vibrational modes in nicotinic acid is assigned to the frequency at $1322 \mathrm{~cm}^{-1}$. It should be noted that the next band at $1194 \mathrm{~cm}^{-1}$ in IR spectrum is assigned to C-F stretching, which is the characteristic vibration peak of $\mathrm{CF}_{3}$ group [32,33]. The absorption at $1140 \mathrm{~cm}^{-1}$ is also due to the stretching type of vibrations of $\mathrm{C}-\mathrm{F}$ bonds. The band at $517 \mathrm{~cm}^{-1}$ is assigned to $\mathrm{C}-\mathrm{C}=\mathrm{O}$ wagging. The characteristics bands, one at $836 \mathrm{~cm}^{-1}$ (COO- rocking), one at $746 \mathrm{~cm}^{-1}$ (COOscissoring) and the third at $622 \mathrm{~cm}^{-1}\left(\mathrm{COO}^{-}\right.$wagging) are observed in the IR spectrum.

\subsection{Dielectric studies}

The dielectric constant is one of the basic electrical properties of solids. Dielectric properties are correlated with the electro-optic property of the crystals [34]. The capacitance ( $\mathrm{C}_{\text {crys }}$ ) and dielectric loss (tan $\delta$ ) of NTF crystal were measured using the conventional parallel plate 
capacitor method with the frequency range $100 \mathrm{~Hz}$ to $1 \mathrm{MHz}$ using the Agilent 4284A LCR meter at various temperatures ranging from 40 to $80^{\circ} \mathrm{C}$. A good quality crystal of size $5 \times 5 \times$ $2 \mathrm{~mm}^{3}$ was electroded on either side with graphite coating to make it behave like a parallel plate capacitor. The observations were made during cooling of the sample. The air capacitance (Cair) was also measured.

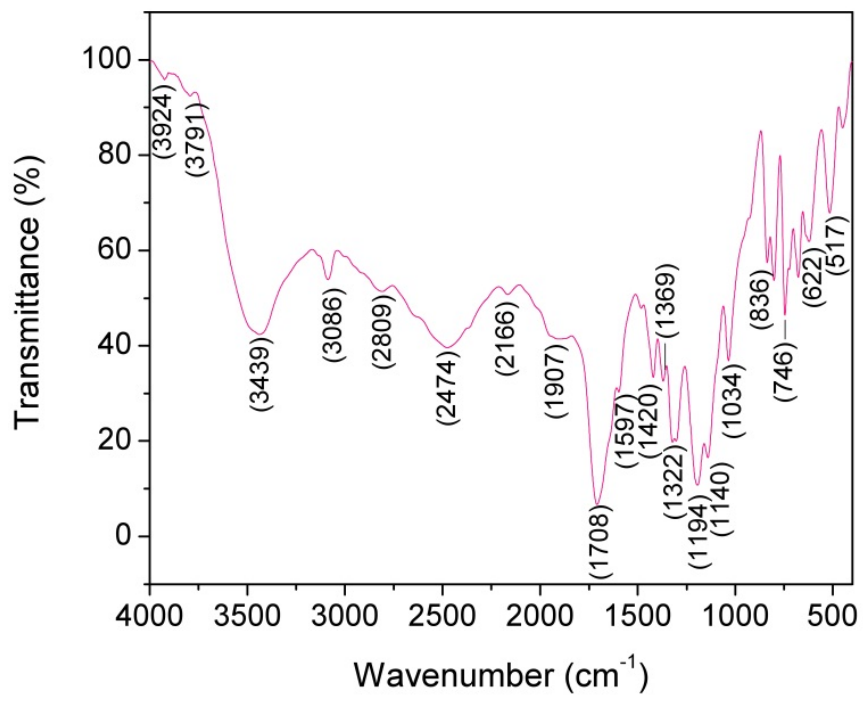

Figure 14. FTIR spectrum of NTF

The dielectric constant $\left(\varepsilon_{\mathrm{r}}\right)$ of the crystal was calculated using the following relation

$$
\varepsilon_{\mathrm{r}}=\frac{\mathrm{C}_{\text {crys }}}{\mathrm{C}_{\text {air }}}
$$

As the crystal area was smaller than the plate area of the cell, parallel capacitance of the portion of the cell not filled with the crystal was taken into account and, consequently the above equation becomes

$$
\varepsilon_{\mathrm{r}}=\left(\frac{\mathrm{C}_{\text {crys }}-\mathrm{C}_{\text {air }}\left(1-\frac{\mathrm{A}_{\text {crys }}}{\mathrm{A}_{\text {air }}}\right)}{\mathrm{C}_{\text {air }}}\right)\left(\frac{\mathrm{A}_{\text {air }}}{\mathrm{A}_{\text {crys }}}\right)
$$

where Acrys is the area of the crystal touching the electrode and Aair is the area of the electrode.

The variation of dielectric constant with frequency at different temperatures (Figure 15) shows that dielectric constant decreases with increasing frequency and finally it becomes 
almost a constant at higher frequencies for all temperatures. It is also indicates that dielectric constant increases with increase in temperature. The measurements of dielectric loss at different frequencies and temperatures show the same trend. This dielectric behavior [35] can be understood on the basis that the mechanism of polarization is similar to that of conduction process. The electronic exchange of the number of ions in the crystals gives local displacement of electrons in the direction of the applied field, which in turn gives rise to polarization namely, electronic, ionic, dipolar and space charge polarization. Space charge polarization is generally active at lower frequencies and high temperatures and indicates the perfection of the crystal. As the frequency increases, a point will be reached where the space charge cannot sustain and comply with the external field and hence the polarization decreases, giving rise to decrease in values of $\varepsilon_{\text {r. }}$ At $80{ }^{\circ} \mathrm{C}$, the dielectric constant of NTF crystal at $100 \mathrm{~Hz}$ is 10.851 , and this value decreases to 1.955 at $1 \mathrm{MHz}$. Lowering the value of dielectric constant of the interlayer dielectric (ILD) decreases the RC delay, lowers the power consumption and reduces the crosstalk between nearby interconnects [36]. Also the materials with quite low dielectric constant lead to a small RC constant, thus permitting a higher bandwidth in the range of $10^{12} \mathrm{~Hz}$ for light modulation. Thus materials with low dielectric constant have considerable advantages in this context.

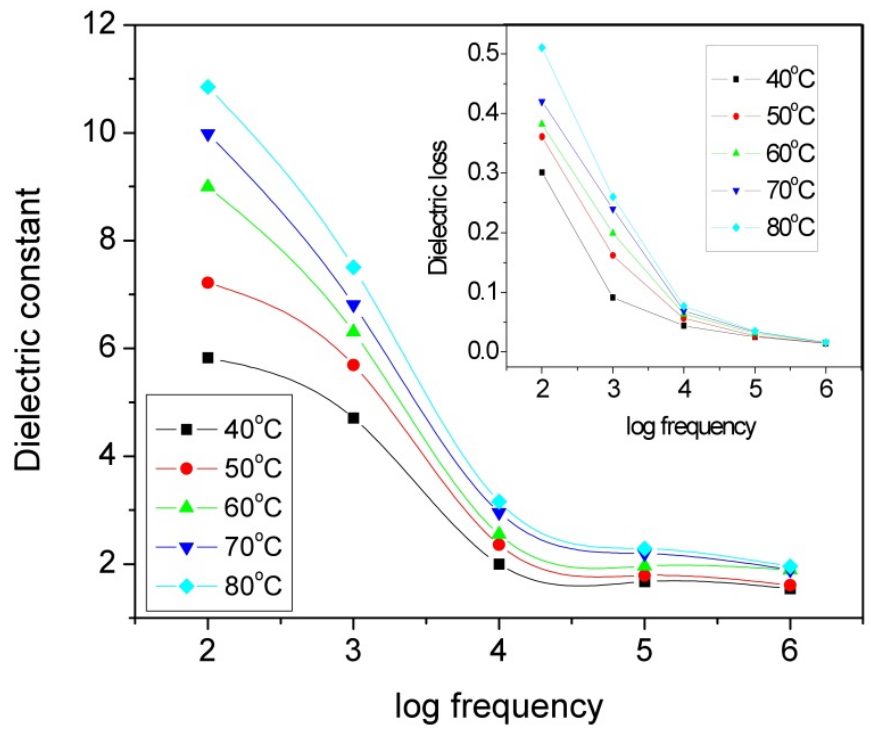

Figure 15. Plot of dielectric constant versus applied frequency. Plot of dielectric loss versus applied frequency is in inset

\subsection{Mechanical hardness studies}

Mechanical strength of the materials plays a key role in the device fabrication. Vickers hardness is one of the important deciding factors in selecting the processing (cutting, grinding and polishing) steps of bulk crystal in fabrication of devices based on crystals. 
Microhardness measurements were done on (112) face of NTF crystal using Leitz-Wetzlar hardness tester fitted with a Vickers diamond indenter at room temperature. The Vickers microhardness number, $\mathrm{Hv}$ was calculated using the relation [37]:

$$
\mathrm{H}_{\mathrm{V}}=1.8544\left(\mathrm{p} / \mathrm{d}^{2}\right) \mathrm{kg} / \mathrm{mm}^{2}
$$

where $\mathrm{p}$ is the applied load $(\mathrm{g})$ and $\mathrm{d}$ is the diagonal length $(\mu \mathrm{m})$ of the indentation. The indentation time was kept at $10 \mathrm{~s}$ and microhardness value was taken as the average of the several impressions made. Figure 16 shows the variation of $\mathrm{Hv}$ as function of applied load in the range $10-100 \mathrm{~g}$ on (112) face of NTF crystal.

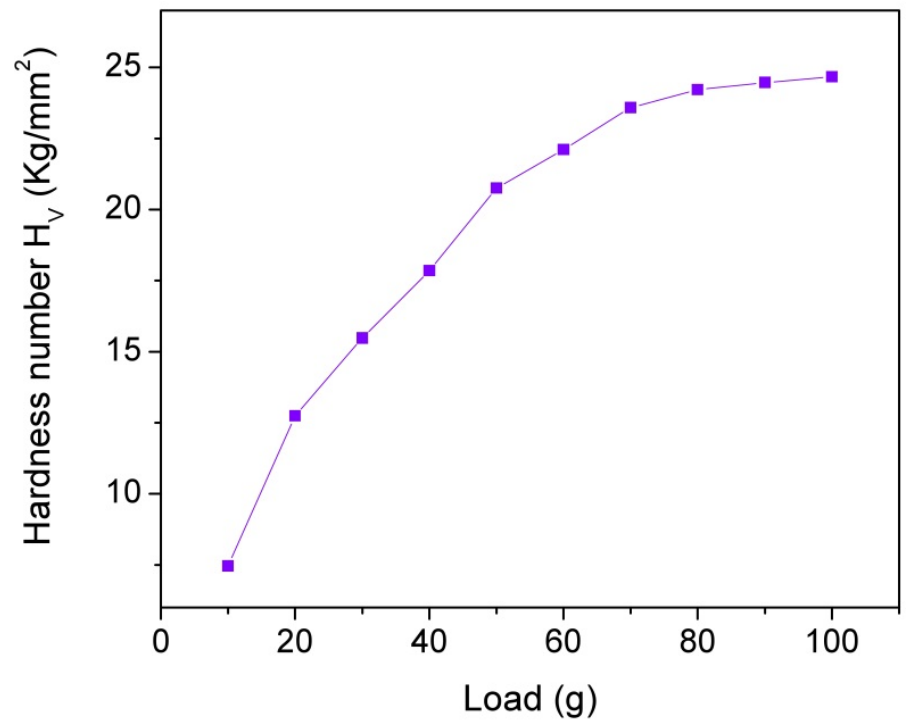

Figure 16. Variation of Vickers microhardness values versus applied load

It reveals that hardness number increases with increasing applied load. This phenomenon is known as reverse indentation size effect (RISE). When the material is deformed by the indenter, dislocations are generated near the indentation site. The major contribution to the increase in hardness is attributed to the high stress required for homogenous nucleation of dislocations in the small dislocation-free region indented [38]. The RISE can be caused by the relative predominance of nucleation and multiplication of dislocations. The other reason for RISE is that the relative predominance of the activity of either two sets of slip planes of a particular slip system or two slip systems below and above a particular load [39]. The RISE phenomenon essentially takes place in crystals which readily undergo plastic deformation [40]. The relation between load and the size of indentation can be interpreted using Meyer's law, $\mathrm{P}=\mathrm{k}_{1} \mathrm{~d}^{\mathrm{n}}$, where $\mathrm{k}_{1}$ is a constant and $\mathrm{n}$ is the Meyer's number (or index). The slope of log $P$ versus $\log d$ gives the $n$ value and it is estimated to be 2.73. According to Onitsch [41] and 
Hanneman [42], $\mathrm{n}$ should be between 1 and 1.6 for hard materials and above 1.6 for softer ones. Thus NTF crystal belongs to soft material category. Meyer number is a measure of the indentation size effect (ISE). For the normal ISE behaviour, the exponent $n<2$. When $n>2$, there is the RISE behaviour [39].

\section{Conclusions}

Single crystals of NTF in monoclinic system were grown by solution growth technique for the first time and its solubility and metastable zone width were determined. X-ray diffraction analysis reveals that NTF crystallizes in monoclinic system with space group I2/a and unit cell parameters are $a=15.616(5) \AA, b=7.455(5) \AA, c=16.503(5) \AA$, and $\beta=95.74^{\circ}$. HRXRD analysis substantiates the good quality of the crystals. TG-DTA and DSC studies show that NTF melts at $152{ }^{\circ} \mathrm{C}$. It is observed that thermal stability of NTF is in between that of other nicotinium derivative crystals. The FTIR analysis confirms the presence of functional groups constituting NTF. Dielectric measurements indicate that NTF crystal has low values of dielectric constant and dielectric loss.

\section{Author details}

P.V. Dhanaraj

Department of Physics, Malabar Christian College, Kozhikode, India

N.P. Rajesh

Centre for Crystal Growth, SSN College of Engineering, Kalavakkam, India

\section{References}

[1] Zyss J, Dhenaut C, Van T C, Ledoux I (1993) Quadratic Nonlinear Susceptibility of Octupolar Chiral Ions. Chem. Phys. Lett. 206: 409-414.

[2] Russell V A, Evans C C, Li W, Ward M D (1997) Nanoporous Molecular Sandwiches: Pillared Two-Dimensional Hydrogen-bonded Networks with Adjustable Porosity. Science 276: 575-579.

[3] Matos Gomes E D, Venkataramanan V, Nogueira E, Belsley M, Proenca F, Criado A, Dianez M J, Estrada M D,Perez-Garrido S (2000) Synthesis, Crystal Growth and Characterization of a Nonlinear Optical Material-Urea L- Malic Acid. Synth. Met. 115: 225-228.

[4] Levine B F, Bethea C G (1975) Conjugated Electron Contributions to the Second Order Hyperpolarizability of Substituted Benzene Molecules. J. Chem. Phys. 63: 6-10.

[5] Bosshard Ch, Knopfle G, Pretre P, Gunter J P (1992) Second-order Polarizabilities of Nitropyridine DerivativesDetermined with Electric-Field-Induced Second-Harmonic Generation and a Solvatochromic Method: A Comparative Study. J. Appl. Phys. 71: 1594-1599. 
[6] Clays K, Persoons A (1991) Hyper-Rayleigh Scattering in Solution. Phys. Rev. Lett. 66: 2980-2983.

[7] Clays K, Olbrechts G, Munters T, Persoons A, Kim O K, Choi L S (1998) Enhancement of the Molecular Hyperpolarizability by a Supramolecular Amylose-Dye Inclusion Complex, Studied by Hyper-Rayleigh Scatteringwith Fluorescence Suppression. Chem. Phys. Lett. 293: 337-342.

[8] Dhenaut C, Ledoux I, Samuel I D W, Zyss J, Bourgault M, Bozec H L (1995) Chiral Metal Complexes with Large Octupolar Optical Nonlinearities. Nature 374: 339-342.

[9] Sylla M, Giffard M, Boucher V, Illien B, Mercier N, Nguyen Phu X (1999) Nonlinear Optical Properties of Chiral Thiolates. Synth. Met. 102: 1548-1549.

[10] Ferrier J L, Gazengel J, Nguyen Phu X, Rivoire G (1984) Backscattering in the Picosecond Range: an Optical Triggered Switching Effect. Opt. Commun. 51 (4): 285288.

[11] Somac M, Somac A, Davies B L, Humphery M G, Wong M S (2002) Third-Order Optical Nonlinearities of Oligomers, Dendrimers and Polymers Derived from Solution Z-Scan Studies. Opt. Mater. 21: 485-488.

[12] Natarajan L V, Sutherland R L, Tondiaglia V P, Bunning T J, Adams W W (1996) Electro-Optical Switching Characteristics of Volume Holograms in Polymer Dispersed Liquid Crystals. J. Nonlinear Opt. Phys. Mater. 5: 89- 98.

[13] Pecaut J, Bagieu-Beucher M (1993) 2-Amino-5-nitropyridiniummonohydrogenphos phite. Acta Cryst. C49: 834-837.

[14] Ravindra H J, John Kiran A, Dharmaprakash S M, Satheesh Rai N, Chandrasekharan K, Kalluraya B, Rotermund F (2008) Growth and characterization of an efficient nonlinear optical D- $\pi-\mathrm{A}-\pi-\mathrm{D}$ type chalcone single crystal. J. Cryst. Growth 310: 4169-4176.

[15] Gielen M, Kholufi A E, Biesemans M, Willem R (1992) (2-Methylthio-3Pyridinecarboxylato)-diethyltin and -di- n-butyltin Compounds: Synthesis, Spectroscopic Characterization and in vitro Antitumour Activity. X-ray Crystal Structure of bis[diethyl(2-methylthio-3-Pyridinecarboxylato)tin] oxide and of diethyltin bis(2-methylthio-3- pyridinecarboxylate), Polyhedron. 11: 1861-1868.

[16] Athimoolam S, Anitha K, Rajaram R K (2005) Nicotinium dihydrogenphosphate. Acta Cryst.E61: o2553-o2555.

[17] Athimoolam S, Rajaram R K (2005) Bis(nicotinic acid) hydrogen perchlorate. Acta Cryst. E61:02674-o2676.

[18] Athimoolam S, Rajaram R K (2005) Dinicotinium sulfate. Acta Cryst. E61: o2764-o2767.

[19] Gao S, Liu J W, Huo L H, Sun Z Z, Gao J S, Ng S W (2004) Catena-Poly[[diaquabis(2chloronicotinato- $\left.\kappa^{2} \mathrm{O}, \mathrm{O}^{\prime}\right)$ cadmium(II)]- $\mu_{-}$-2-chloronicotinato- $\left.\kappa^{3} \mathrm{O}, \mathrm{O}^{\prime}: \mathrm{N}\right]$. Acta Cryst. C 60: m363-m365.

[20] Athimoolam S, Natarajan, S (2007) Nicotinium trifluoroacetate. Acta Cryst. E 63: 26562657.

[21] Nyvlt J, Rychly R, Gottfried J, Wurzelova J (1970) Metastable Zone-Width of Some Aqueous Solutions. J. Cryst. Growth 6: 151-162. 
[22] Sangwal K (1989) On The Estimation of Surface Entropy Factor, Interfacial Tension, Dissolution Enthalpy and Metastable Zone-Width for Substances Crystallizing from Solution. J. Cryst. Growth 97: 393-405.

[23] Harms K, Wocadlo S, XCAD4, University of Marburg, Germany, 1995.

[24] North A C T, Phillips D C, Mathews F S (1968) A semi-empirical method of absorption correction. Acta Cryst. A24: 351-359.

[25] SHELXTL/PC Version 6.10 Madison, WI: Bruker AXS Inc., 2000.

[26] Lal K, Bhagavannarayana G (1989) A High-Resolution Diffuse X-Ray Scattering Study of Defects in Dislocation-Free Silicon Crystals Grown by the Float-Zone Method and Comparison with Czochralski-Grown Crystals. J. Appl. Cryst. 22: 209-215.

[27] Bonse U, Hart M (1965) Tailless X-ray Single Crystal Reflection Curves Obtained by Multiple Reflection. Appl. Phys. Lett. 7: 238-240.

[28] Bhagavannarayana G (1994) High Resolution X-Ray Diffraction Study of As-Grown and $\mathrm{BF}_{2}{ }^{+}$Implanted Silicon Single Crystals, Ph. D. Thesis, University of Delhi, Delhi, India.

[29] Bhagavannarayana G, Kushwaha S K (2010) Enhancement of SHG Efficiency by Urea Doping in ZTS Single Crystals and its Correlation with Crystalline Perfection as Revealed by Kurtz Powder and High-Resolution X-Ray Diffraction Methods. J. Appl. Cryst. 43: 154-162.

[30] Bhagavannarayana G, Ananthamurthy R V, Budakoti G C, Kumar B, Bartwal K S (2005) A Study of the Effect of Annealing on Fe-Doped $\mathrm{LiNbO}_{3}$ by HRXRD, XRT and FT-IR. J. Appl. Cryst. 38: 768-771.

[31] Willard, Merritt, Dean, Settle (1986) Instrumental Methods of Analyses, First Indian Edition: CBS, Delhi.

[32] Fuson N, Josien M L, Jones E A, Lawson J R (1952) Infrared and Raman Spectroscopy Studies of Light and Heavy Trifluoroacetic Acids. J. Chem. Phys. 20: 1627-1635.

[33] Takeda Y, Suzuki H, Notsu K, Sugimoto W, Sugahara Y (2006) Preparation of a Novel Organic Derivative of the Layered Perovskite Bearing $\mathrm{HLaNb}_{2} \mathrm{O}_{7} \cdot \mathrm{nH}_{2} \mathrm{O}$ Interlayer Surface Trifluoroacetate Groups. Mat. Res. Bull. 41: 834-841.

[34] Aithal P S, Nagaraja H S, Mohan Rao P, Avasti D K, Sarma A (1997) Effect of high energy ion irradiation on electrical and optical properties of organic nonlinear optical crystals. Vacuum 48: 991-994.

[35] Anderson J C (1964) Dielectrics, Chapman and Hall.

[36] Hatton B D, Landskron K, Hunks W J, Bennett M R, Shukaris D, Pervoic D D, Ozin G A (2006) Materials Chemistry for Low k-Materials. Mater. Today. 9: 22-31.

[37] Mott B W (1956) Microindentation Hardness Testing, Butterworths, London.

[38] Kunjomana A G, Chandrasekharan K A (2005) Microhardness Studies of GaTe Whiskers. Cryst. Res. Technol. 40: 782-785.

[39] Sangwal K (2000) On the Reverse Indentation Size Effect and Microhardness Measurement of Solids. Mater. Chem. Phys. 63: 145-152.

[40] Li H, Han Y H, Bradt R C (1994) Knoop Microhardness of Single Crystal Sulphur. J. Mater. Sci. 29: 5641-5645. 
Applications of Calorimetry in a Wide Context -

70 Differential Scanning Calorimetry, Isothermal Titration Calorimetry and Microcalorimetry

[41] Onitsch E M (1947) Mikroscopia 2: 131-134.

[42] Hanneman M (1941) Metall. Manch. 23: 135-139. 